\title{
TYPES OF COMPOUND WORD-FORMATION IN MEDICAL TERMINOLOGY (ON THE MATERIAL OF THE GERMAN LANGUAGE)
}

\author{
Marina I. Nosacheva \\ Saratov State Medical University named after V.I. Razumovsky, Saratov, Russia \\ Nataliya I. Danilina \\ Saratov State Medical University named after V.I. Razumovsky, Saratov, Russia
}

\begin{abstract}
The aim of the study is to optimize the classification of the types of the compound word-building with components of Greek and Latin origin; the research is based on the sample of 2882 substantive compound terms of the German clinical terminology. The researches apply the descriptive analytical and quantitative methods to the study. It is stated, that the words with complex morphemic structures can be formed by composite and non-composite types of word-building. The paper presents the complex classification of different ways of the compound word-formation considering following criteria: the type and the base of the word-formation process (morphological and morphologicaland-syntactic ways of the compound word-formation), the number of the word-building processes, taking place within the compound word-formation (pure and mixed types of the compound word-formation). The analysis of the material reveals the dominance of the morphological compound word-building. In the medical terminology the following subtypes of the compound word-formation are distinguished: stem + terminological element, term + term, stem + term, with the latter two to be the most productive. The use of terminological units as structural elements of compounds and their employment in classification allows to avoid excessive extension of stock of morphemes used in the so-called intermediate zone. Further arrangement of word-building patterns is carried out according to the genetic criterion. In German clinical terminology the dominance of hybrid terms with German components has been established; among homogeneous compounds the terms consisting of Greek rather than Latin or German components are more widely represented. The proposed classifications are applicable to the material of medical terminologies in other languages and enable their accurate comparison.
\end{abstract}

Key words: word-formation type, word composition, compound word, terminological element, interfix, medical terminology, German language.

Citation. Nosacheva M.I., Danilina N.I. Types of Compound Word-Formation in Medical Terminology (On the Material of the German Language). Vestnik Volgogradskogo gosudarstvennogo universiteta. Seriya 2. Yazykoznanie [Science Journal of Volgograd State University. Linguistics], 2019, vol. 18, no. 4, pp. 145-156. (in Russian). DOI: https://doi.org/10.15688/jvolsu2.2019.4.11

\section{СПОСОБЫ ОБРАЗОВАНИЯ СЛОЖНЫХ СЛОВ В МЕДИЦИНСКОЙ ТЕРМИНОЛОГИИ (НА МАТЕРИАЛЕ НЕМЕЦКОГО ЯЗЫКА)}

\section{Марина Игоревна Носачёва}

Саратовский государственный медицинский университет им. В.И. Разумовского, г. Саратов, Россия

\section{Наталия Ивановна Данилина}

Саратовский государственный медицинский университет им. В.И. Разумовского, г. Саратов, Россия 
Аннотация. Цель исследования состоит в оптимизации классификации способов образования композитов с участием компонентов греко-латинского происхождения. Материалом послужила выборка субстантивных композитов немецкой клинической терминологии (2 882 термина). Использованы описательно-аналитический и количественный методы. Показано, что сложные по морфемному составу слова могут быть образованы композитными и некомпозитными способами. Предложена комплексная классификация композитных способов терминообразования, учитывающая тип базиса (морфологические и морфолого-синтаксические способы), количество процессов, одновременно происходящих в акте словообразования (чистые и смешанные способы). Установлено, что в немецкой клинической терминологии доминирует морфологическое словосложение. Данный способ применительно к медицинской терминологии дифференцирован по типу складываемых компонентов: собственно словосложение, основа + термин, основа + терминоэлемент. Выявлено, что наиболее продуктивными являются сложение с термином и собственно словосложение. Доказано, что признание терминоэлемента структурной составляющей композитов и использование его в классификации способов композитообразования позволяет отказаться от чрезмерного расширения инвентаря морфем переходной зоны. Дальнейшая группировка словообразовательных моделей проведена по генетическому критерию. Установлено, что в немецкой клинической терминологии преобладают терминыгибриды с немецкими компонентами; из гомогенных композитов греческие представлены шире, чем латинские и немецкие. Предложенные в статье классификации применимы к материалу медицинских терминосистем других языков и обеспечивают возможность их корректного сопоставления.

Ключевые слова: способ словообразования, словосложение, композит, терминоэлемент, интерфикс, медицинская терминология, немецкий язык.

Цитирование. Носачёва М. И., Данилина Н. И. Способы образования сложных слов в медицинской терминологии (на материале немецкого языка) // Вестник Волгоградского государственного университета. Серия 2, Языкознание. - 2019. - Т. 18, № 4. - C. 145-156. - DOI: https://doi.org/10.15688/jvolsu2.2019.4.11

\section{Введение}

Словосложение, под которым традиционно понимается соединение двух или более корневых морфем / слов в сложное слово (Bußmann, 1990, S. 400), - один из древнейших способов словообразования в индоевропейских языках [Степанова, 1953, с. 109; Meillet, 1908, p. 257; Schleicher, 1861, S. 290]. Роль его в современных языках может быть различной. В русском языке он относится к периферии словообразовательной системы: существительных, образованных чистым сложением, немного, среди них преобладают слова с интернациональными компонентами, входящие в сферу научно-технической терминологии [Русская грамматика, 1980, с. 243-246]. В немецком словосложение, напротив, является важнейшим и продуктивным способом словообразования, что отмечается и в фундаментальных грамматиках [Eichinger, 2000, S. 71; Eichler, Bünting, 1996, S. 230], и в исследованиях, выполненных на материале языка СМИ ХХІ в. [Жилюк, 2016; Elsen, Dzikowicz, 2005, S. 81, 82]. Поэтому в целом в трудах германистов теория сложного слова разработана детальнее, чем в русистике, но некоторые ее аспекты, в частности проблемы переход- ной зоны между способами словообразования и отграничение композитов от смежных явлений, остаются актуальными и дискуссионными [Elsen, Michel, 2007, S. 4-5]. Так, предлагается оптимизация традиционных критериев на материале немецкого языка [Груздева, 2012; Юшкова, 2018], шкалирование морфем переходной зоны в зависимости от продуктивности и частотности на материале английского языка (см.: Бартков, 2018), полевая концепция сложного слова на материале русского языка [Гудилова, 2005]. Нельзя не отметить попытки скоординировать терминосистемы разных национальных школ [Иванова, Аржанцева, 2012], чтобы обеспечить возможность дальнейших сопоставительных исследований.

Поскольку в русском языке сферой бытования композитов является преимущественно терминология, изучение данного участка системы других языков представляется актуальным с точки зрения перспектив сопоставительных исследований. К способам словообразования, активизировавшимся в современных языках для специальных целей, В.М. Лейчик относит: лексикализацию словосочетаний, аббревиацию, усечение, сложносокращенный способ, телескопию, полуаффиксацию [Лейчик, 2007, с. 54-57]. Сходство этих способов с тра- 
диционным словосложением очевидно: все они имеют результатом совмещение в одной лексеме нескольких понятий, связываемых с отдельной корневой морфемой, ср. трактовку, предложенную в «Русской грамматике» [Русская грамматика, 1980, с. 139]. Анализ соотношения разных способов терминообразования в рамках одной терминосистемы и выявление характерных тенденций в этой сфере могут стать материалом для сопоставительного анализа как терминосистемы и литературного языка, так и различных национальных терминосистем.

Объектом изучения в данной статье выбрана немецкая терминология клинической медицины. Ее специфика в сравнении с литературным языком заключается в широкой представленности в структуре терминов морфем греческого и латинского происхождения, что традиционно отмечается исследователями (см., например: [Федорцова, 1984]). Эта черта характеризует и другие национальные медицинские терминосистемы, в частности русскую и английскую [Архипова, Гущина, 2012; Носачёва, 2017], а также терминологии смежных дисциплин [Хакимова, 2018, с. 184, 188]. Исследователи, как правило, уделяют внимание описанию структуры и семантики конкретных моделей, в то время как морфемный статус греко-латинских компонентов и их роль в системе способов словообразования не получают четкой теоретической интерпретации в работах терминологов. Показателен вывод В.Н. Федорцовой: «...последовательное размежевание аффиксов и корней в ряду связанных морфем греко-латинского происхождения невозможно. В связи с этим в системе интернационального медицинского терминообразования невозможно выделить традиционные модели словосложения, префиксации и суффиксации» [Федорцова, 1984, c. 186-187]. Все это делает медицинскую терминологию актуальным объектом анализа в аспекте уточнения теоретического аппарата дериватологии.

\section{Материал и методы исследования}

Нами была произведена выборка клинических терминов из «Roche Lexikon Medizin». Ее общий объем - 5155 единиц. Сложные тер- мины, зафиксированные в этой выборке, составили 2882 единицы (55,9\%), что свидетельствует о существенной роли композитов в немецкой клинической терминологии. Задачами статьи являются классификация способов образования сложных слов, фиксируемых в анализируемом материале, и установление роли каждого из них в изучаемой терминосистеме на основе количественного анализа. В соответствии с ними используются описательно-аналитический и количественный методы.

\section{Результаты и обсуждение}

\section{Способы образования сложных слов.}

Если понимать под сложным слово, включающее несколько корневых морфем, можно заметить, что не все такие слова образованы способом словосложения. Например, слова hochsommerlich, Eisenbahner, $m$, Schullehrerin, $f$ появились в результате прибавления суффикса к основе сложного слова (Hochsommer- + -lich, Eisenbahn- + -er, Schullehrer- + -in). В таких случаях наблюдается противоречие между морфемной структурой слова и способом его образования, то есть несовпадение результатов морфемного и словообразовательного членения. Сказанное означает, что могут быть выделены сложные слова, образованные композитными и некомпозитными способами. К первым следует отнести такие, которые включают соединение в словообразовательном акте нескольких корней (свободных или связанных) / основ / слов, ко вторым - присоединение форманта к основе, уже содержащей несколько корней в результате предшествующих актов словообразования. Учет данной дихотомии принципиально важен при словообразовательном анализе: словосложение всегда приводит к образованию композита, в то время как не каждое сложное слово появляется в результате словосложения.

К некомпозитным способам образования сложных слов относятся аффиксальные способы и сокращение. При аффиксальном способе формант прибавляется к основе сложного слова (Außenseiter- + -isch $=$ außenseiterisch, un- + Gleichgewicht, $n=$ Ungleichgewicht, $n)$. При сокращении в качестве единственного словообразовательного процесса выступает опускание одного или нескольких компо- 
нентов сложного слова (Elektromobil, $n$ от Elektroautomobil, $n$ ).

Некомпозитные способы образования клинических терминов. В нашем материале сложные термины, образованные некомпозитными способами, составили 1,9\%. Полученные в результате анализа количественные данные и примеры представлены в таблице 1.

Как можно видеть, наиболее частотным среди аффиксальных способов образования композитов является суффиксация (72,5 \% всех терминов, образованных этими способами, наиболее продуктивны при этом суффиксы -osis / -ose (16 терминов) и -от / -ота (10 терминов).

Композитные способы образования сложных слов. Обратимся к классификации композитных способов словообразования, то есть таких, в которых содержание словообразовательного акта составляет соединение компонентов. Ввести понятие «композитные способы» побуждает существование широкого и узкого понимания термина «композиция». С одной стороны, под композицией (словосложением) понимается любое соединение корневых морфем / основ / слов в сложное слово (см. об этом: Петров, 2003, с. 4), а также: [Степанова, Фляйшер, 1984, с. 116; Engel, 1994, S. 84]). Интерпретируемая таким образом, она включает, кроме словосложения, разнородные словообразовательные процессы: универбацию (die Analgetika от словосочетания analgetische Mittel), сращение (das Gelverdienen) и др. С другой стороны, к словосложению, как отмечает У. Энгель, иногда не относятся такие процессы, при которых базисом для образования сложного слова являются не сло- ва, а словосочетания (zweibeinig) [Engel, 1994, S. 85].

В связи с этим целесообразно прибегнуть к делению способов словообразования на морфологические и неморфологические, восходящему к классификации В.В. Виноградова, различавшего морфологические, морфолого-синтаксические, лексико-синтаксические, лексико-семантические способы [Виноградов, 1975, c. 156]. При анализе нашего материала релевантной оказалась дифференциация способов композитообразования на морфологические и морфолого-синтаксические, поскольку композиция в широком смысле подразделяется на морфологическую (на основе отдельных слов) и морфолого-синтаксическую (на базе словосочетаний). При этом проведение четких границ между названными способами представляется затруднительным ввиду тесной взаимосвязи морфологических и синтаксических процессов. Например, сложносокращенный способ на базе слова (U-Bahn, $f$ от Untergrundbahn, $f$ ) может быть отнесен к морфологическим, а на основе словосочетания (DB от deutsche Bahn) - к морфолого-синтаксическим способам.

В зависимости от количества процессов, взаимодействующих в акте словообразования, и морфологические, и морфологосинтаксические способы подразделяются на чистые и смешанные. К чистым относятся словосложение в узком смысле слова, то есть соединение двух или более корней / основ / слов в одно сложное слово (die Eisenbahn, die Doktorarbeit), и сложносокращенный способ на базе словосочетания (die Gesellschaft

Таблица 1

Количественная представленность некомпозитных способов образования сложных терминов

\begin{tabular}{|c|c|c|c|c|}
\hline \multirow{2}{*}{\multicolumn{2}{|c|}{ Способ образования }} & \multirow{3}{*}{$\begin{array}{c}\begin{array}{c}\text { Кол-во } \\
\text { терминов }\end{array} \\
37\end{array}$} & \multicolumn{2}{|c|}{ Кол-во компонентов, примеры } \\
\hline & & & 2 & 3 \\
\hline \multirow[t]{3}{*}{ Аффиксальный } & Суффиксальный & & $\begin{array}{c}36 \\
\text { Adenofibromatosis, } f\end{array}$ & $\begin{array}{c}1 \\
\text { Megakaryozytose, } f\end{array}$ \\
\hline & Префиксальный & 12 & $\begin{array}{c}11 \\
\text { Präleukämie, } f\end{array}$ & $\begin{array}{c}1 \\
\text { Paraosteoarthropathie, } f\end{array}$ \\
\hline & $\begin{array}{l}\text { Префиксально- } \\
\text { суффиксальный }\end{array}$ & 2 & $\begin{array}{c}2 \\
\text { Agranulozytose, } f\end{array}$ & - \\
\hline \multicolumn{2}{|l|}{ Сокращение } & 4 & $\begin{array}{c}4 \\
\text { Mukotympanum } \\
(<\text { Seromukotympanum }) \\
\end{array}$ & - \\
\hline & Итого & 55 & 53 & 2 \\
\hline
\end{tabular}


mit beschränkter Haftung $=G m b H)$. При взаимодействии в акте композитообразования нескольких процессов можно говорить о смешанных способах словообразования. К таковым относятся парасинтетические, то есть сложение на базе слова в сочетании с аффиксацией $($ Straf- + verfolg- + -er $=$ Strafverfolger, $m)$, и сращение, то есть сложение на базе словосочетания в сочетании с аффиксацией, конверсией или стяжением (schnell laufen $+-e r=$ Schnellläufer, m) [Степанова, 1953, с. 192].

Все сложные слова, образованные композитными способами (кроме сращений), в зависимости от отсутствия / наличия соединительного элемента (интерфикса) подразделяются на полносложные и неполносложные. Это деление, восходящее к классификации Я. Гримма [Grimm, 1831, S. 407-408], получает развитие в трудах немецких и русских германистов [Степанова, 1953, с. 110-112; Behaghel, 1930, S. 258; Henzen, 1957, S. 3637] и в настоящее время может использоваться в качестве критерия формальной дифференциации моделей в рамках структурной классификации.

Приведенная выше классификация способов композитообразования может получить дальнейшее уточнение при рассмотрении терминологического словосложения.

Композитные способы образования в клинической терминологии. Одной из тенденций медицинского терминологического композитообразования является широкое использование компонентов греко-латинского происхождения, поэтому представляется целесообразным дать теоретическую интерпретацию их морфемного состава и дифференцировать способ словосложения в зависимости от статуса соединяемых компонентов.

Во-первых, может быть выделено собственно словосложение- способ, при котором всеми компонентами композита становятся самостоятельные слова. Структурной особенностью данной разновидности является отсутствие интерфикса между этими компонентами и, как правило, дефисное написание. В качестве первого компонента в большинстве терминов выступает имя собственное, финального - греческий по происхождению термин Syndrom, $n$, латинский Operation, $f$, а также немецкие (Krankheit, $f$, Zeichen, $n$ ).
Во-вторых, самостоятельным термином может быть только финальный компонент сложения (как национального, так и греко-латинского происхождения), остальными компонентами в этом случае служат основы терминов или греко-латинские терминоэлементы, например: Muldenplastik, $f$, Abspreizzeichen, $n$.

B-третьих, финальными компонентами сложного термина могут являться греко-латинские терминоэлементы (далее - ТЭ), не существующие в немецком языке в качестве самостоятельных слов, структурно представляющие собой морфемный комплекс «корень + суффикс + флексия». Возможность рассматривать термины типа Proktoskopie, $f$, Mikromyelie, $f$ как образованные словосложением, а не сложноаффиксальным способом (например, prokt- + $s k o p+$ суффикс -ie) объясняется тем, что финальные ТЭ, соотносящие термин с тем или иным понятием клинической медицины, воспроизводятся в терминологическом словосложении в готовом виде. В свою очередь комплексные ТЭ, как было показано М.И. Носачёвой на материале русского языка [Носачёва, 2018], делятся на сложные, то есть комплексы с идиоматизированной семантикой, в которых семантика ТЭ невыводима напрямую из семантики корня (-loge, -logia, -skop, -skopia и др.), и псевдосложные, в которых суффиксально-флексийная часть не меняет семантики корня, а служит лишь грамматическому оформлению слова (-kardie, - -myelie и т. д.).

Таким образом, с учетом особенностей структуры клинического термина словосложение в сфере клинической терминологии можно разделить на собственно словосложение, сложение с самостоятельным термином, сложение со сложным ТЭ и сложение с псевдосложным ТЭ.

Неполносложные композиты с интерфиксами в медицинском терминообразовании имеют ряд особенностей. В большинстве композитов греко-латинского происхождения в качестве соединительного элемента используется интерфикс -о-, заимствуемый из греческой модели словосложения: Myodegeneration, $f$, Palatoplastik, $f$. В состоящих из компонентов греко-латинского и национального происхождения, а также в национальных терминах используются немецкие интерфиксы -s-, -(e)nи др., например Arterienverschluss, m, 
Milchdrüsenentzündung, $f$. В некоторых терминах корневые ТЭ имеют греко-латинское происхождение, а единственным национальным компонентом является немецкий интерфикс: Aortenatresie, $f$, Aspirationspneumonie, $f$.

Композитные способы словообразования в немецкой клинической терминологии. Представленность композитов, образованных разными способами, в нашем материале отражают таблицы 2-4. В них рядом с названием каждого способа указано количество терминов, встретившихся в выборке.

Как видно из приведенных данных, словосложение со всеми его разновидностями самый продуктивный способ композитообразования в клинической терминологии $(91,5 \%$ всех композитных терминов выборки). Наибольшее количество композитных терминов образуется путем сложения ТЭ / основы тер- мина с самостоятельным термином / словом и собственно словосложением. Доля терминов, полученных сложением ТЭ/ основы термина и сложного или псевдосложного ТЭ, составляет 18,6 \% всех терминов, возникших в результате словосложения.

Большинство терминов, образованных сложением $(63,9 \%),-$ полносложные композиты. Преобладание полносложных конструкций среди сложений с самостоятельным термином является результатом активного использования, наряду с греко-латинскими ТЭ, национальных компонентов, что допускает большую вариативность в способах соединения компонентов термина. Термины, образованные сложением ТЭ / основы термина с ТЭ, состоят из компонентов греко-латинского происхождения, что обусловливает применение греческих моделей с интерфиксом -о-

Словосложение в композитном терминообразовании

Таблича 2

\begin{tabular}{|c|c|c|c|c|c|c|}
\hline \multirow{2}{*}{$\begin{array}{c}\text { Способ } \\
\text { сложения }\end{array}$} & \multirow{2}{*}{$\begin{array}{c}\text { Кол-во } \\
\text { терминов }\end{array}$} & \multicolumn{5}{|c|}{ Кол-во компонентов, примеры } \\
\hline & & 2 & 3 & 4 & 5 & $>5$ \\
\hline $\begin{array}{l}\text { Сложение ТЭ / } \\
\text { основы термина с } \\
\text { термином }\end{array}$ & 1627 & $\begin{array}{c}1106 \\
\text { Pulmosklero- } \\
\text { se, } f\end{array}$ & $\begin{array}{c}437 \\
\text { Angiofibroli- } \\
\text { pom, } n\end{array}$ & $\begin{array}{c}67 \\
\text { Mastzellenleuk } \\
\text { ämie, } f\end{array}$ & $\begin{array}{c}12 \\
\text { Postmyo- } \\
\text { kardinfarkt- } \\
\text { Syndrom, } n\end{array}$ & $\begin{array}{c}5 \\
\text { Autoimmunpo- } \\
\text { lyendokrinopa- } \\
\text { thie, } f\end{array}$ \\
\hline $\begin{array}{l}\text { Сложение ТЭ / } \\
\text { основы термина } \\
\text { со сложным ТЭ }\end{array}$ & 235 & $\begin{array}{c}194 \\
\text { Pädiater, } m\end{array}$ & $\begin{array}{c}34 \\
\text { Pyeloneosto- } \\
\text { mie, } f\end{array}$ & $\begin{array}{c}7 \\
\text { Adrenomyelo- } \\
\text { neuropathie, } f\end{array}$ & - & - \\
\hline $\begin{array}{l}\text { Сложение ТЭ / } \\
\text { основы термина с } \\
\text { псевдосложным } \\
\text { ТЭ }\end{array}$ & 251 & $\begin{array}{c}239 \\
\text { Myalgie, } f\end{array}$ & $\begin{array}{c}11 \\
\text { Mikroteleop- } \\
\text { sie, } f\end{array}$ & $\begin{array}{c}1 \\
\text { Meningomye- } \\
\text { locystocele, } n\end{array}$ & - & - \\
\hline $\begin{array}{l}\text { Собственно } \\
\text { сложение }\end{array}$ & 502 & $\begin{array}{c}314 \\
\text { Adams- } \\
\text { Operation, } f\end{array}$ & $\begin{array}{c}155 \\
\text { Aase-Smith- } \\
\text { Syndrom, } n\end{array}$ & $\begin{array}{c}28 \\
\text { Petges-Cléjat- } \\
\text { Jacobi- } \\
\text { Krankheit, } f\end{array}$ & $\begin{array}{c}5 \\
\text { Abderhalden- } \\
\text { Fanconi- } \\
\text { Kaufmann- } \\
\text { Lignac- } \\
\text { Syndrom, } n\end{array}$ & - \\
\hline Итого & 2615 & 1853 & 637 & 103 & 17 & 5 \\
\hline
\end{tabular}

Таблича 3

Парасинтетические композитные способы терминообразования

\begin{tabular}{|r|c|c|c|c|}
\hline \multirow{2}{*}{ Способ образования } & \multirow{2}{*}{$\begin{array}{c}\text { Кол-во } \\
\text { терминов }\end{array}$} & 2 & 3 & \multicolumn{3}{|c|}{ Кол-во компонентов, примеры } \\
\cline { 3 - 5 } & 62 & $\begin{array}{c}51 \\
\text { Сложносуффиксальный }\end{array}$ & $\begin{array}{c}11 \\
\text { Myeloosteofibrose, } f\end{array}$ & - \\
\hline Сложнопрефиксальный $f$ & 42 & $\begin{array}{c}36 \\
\text { Abiotrophie, } f\end{array}$ & $\begin{array}{c}5 \\
\text { Parakolostomieher- } \\
\text { nie, } f\end{array}$ & $\begin{array}{c}\text { Abetalipoproteinä- } \\
\text { mie, } f\end{array}$ \\
\hline $\begin{array}{l}\text { Префиксально- } \\
\text { сложносуффиксальный }\end{array}$ & 5 & 5 & - & - \\
\hline Итого & 109 & Pericholangitis, $f$ & 16 & 1 \\
\hline
\end{tabular}


М.И. Носачёва, Н.И. Данилина. Способы образования сложных слов в медицинской терминологии

Таблица 4

Морфолого-синтаксические композитные способы терминообразования

\begin{tabular}{|c|c|c|c|c|}
\hline \multirow{2}{*}{$\begin{array}{c}\text { Способ } \\
\text { образования }\end{array}$} & \multirow{2}{*}{$\begin{array}{l}\text { Кол-во } \\
\text { терминов }\end{array}$} & \multicolumn{3}{|c|}{ Кол-во компонентов, примеры } \\
\hline & & 2 & 3 & 4 \\
\hline $\begin{array}{l}\text { Сложносокра- } \\
\text { щенный }\end{array}$ & 63 & $\begin{array}{c}55 \\
\text { M.R.K.-Syndrom, } n \\
\end{array}$ & $\begin{array}{c}8 \\
\text { Atrioseptopexie, } f\end{array}$ & \\
\hline Сращение: & 14 & & & \\
\hline $\begin{array}{l}\text { a) Сложение + } \\
\text { конверсия }\end{array}$ & 4 & $\begin{array}{c}4 \\
\text { Münzenzählen, } n\end{array}$ & & \\
\hline $\begin{array}{l}\text { б) Сложение + } \\
\text { аффиксация }\end{array}$ & 1 & $\begin{array}{c}1 \\
\text { Mädchenfänger, } m\end{array}$ & & \\
\hline $\begin{array}{l}\text { в) Сложение + } \\
\text { стяжение }\end{array}$ & 9 & & $\begin{array}{c}4 \\
\text { Arteria-praerolandica- } \\
\text { Syndrom, } n \\
\end{array}$ & $\begin{array}{c}5 \\
\text { Arteria-parieto-occipitalis-Syndrom, } \\
\text { Alice - im - Wunderland-Syndrom, } n\end{array}$ \\
\hline Итого & 77 & 60 & 12 & 5 \\
\hline
\end{tabular}

и объясняет доминирование неполносложных композитов.

Парасинтетическими способами образовано небольшое количество терминов выборки $(3,8 \%)$, наиболее продуктивной разновидностью среди них является сложносуффиксальный способ. Из аффиксов бо́льшую продуктивность имеют суффиксы -itis (21 термин) и -ose / -osis (16 терминов), префикс $a$ - / an(34 термина).

На морфолого-синтаксические способы приходится всего 2,7 \% от общего количества композитов выборки.

Модели композитного терминообразования в клинической терминологии. Лексические единицы, образованные тем или иным способом, группируются обычно в словообразовательные типы, выделяемые по признакам словообразующего средства, словообразовательного значения и части речи производящей основы [Русская грамматика, 1980, с. 135]. Очевидно, что к композитам данные критерии трудно применимы. Все исследователи медицинской терминологии предпочитают использовать понятие модели. Количество моделей, которыми оперируют терминологи, бывает велико, поэтому в зависимости от целей конкретного исследования они могут быть объединены по тем или иным критериям. Для медицинской терминологии релевантной представляется генетическая группировка, позволяющая установить роль национального и греко-латинского морфемных фондов в формировании композитов.

Все модели могут быть объединены в два класса: гомогенные, компоненты которых имеют одинаковое происхождение, и гибридные, включающие компоненты разного происхожде- ния. В нашей выборке доминируют термины, образованные по гибридным моделям. При этом 18,8 \% единиц образованы комбинацией греческих компонентов с латинскими, а 37,7 \% композитов включают также национальные компоненты. Например, в термине Abduktionssyndrom, $n$ латинский корень при помощи немецкого интерфикса присоединяется к греческому термину. Среди композитов, образованных по гомогенным моделям, преобладают греческие (30 \% всей выборки), но встречаются также латинские и немецкие, например: Pankreasdiabetes, $m$ (греч.), Affenpocken, $n$ (нем.), Mammaabszess, $m$ (лат.).

Квалификация морфем переходной зон bl. Для определения способа образования каждого конкретного термина следовало принять решения относительно квалификации морфем переходной зоны. Взяв за основу традиционные критерии серийности и семантического сдвига [Груздева, 2012], мы дополнили их критериями позиционной закрепленности [Гущина, 2003; Данилина, 2012; Michel 2011], способности к употреблению в качестве связанного корня в простых словах [Ваганова, 2013], частеречной вариативности [Elsen, 2005], конкретности / обобщенности семантики [Elsen, 2009]. Каждому из критериев было приписано условное количественное значение $(0,1-0,2)$. Морфема, получающая в сумме 1 (серийная, имеющая обобщенное значение и семантический сдвиг в сравнении с этимоном, позиционно закрепленная, оформляющая термины только одной части речи, неспособная выступать корнем простого слова), признается аффиксом, а набирающая от 0,2 до 0,9 переходной. Морфемы переходной зоны мы разделили на частотные компоненты композитов $(0,2-0,5)$ и полуаффиксы $(0,6-0,9)$. В ре- 
зультате статус полуаффиксов получили 4 ТЭ (makr-, -penie, -pexie, -zele), а статус частотных компонентов - 22 (all-, aut-, multi-, poly-, -rrhagie, -rrhö, -tom и др.).

Таким образом, сложение и аффиксация как способы терминообразования не имеют четких границ. Композиты, образованные сложением с самостоятельным термином, могут иметь в начальной позиции частотный компонент, что «размывает» границу с префиксальным способом, а композиты, образованные сложением с ТЭ, могут иметь в составе ТЭ-полусуффикс, что «размывает» границу с суффиксацией. Однако количественные подсчеты показывают, что модели с морфемами переходной зоны не занимают ведущего места в общей системе способов словообразования, и сами способы дифференцируются достаточно четко. Проиллюстрируем этот вывод таблицей 5 , в которой представлены количественные данные по наиболее многочисленной группе терминов - двухкомпонентным композитам, образованным сложением.

Мы полагаем, что введение в классификацию ТЭ в качестве самостоятельной структурной единицы способствует разграничению способов словообразования, а традиционное шкалирование единиц переходной зоны представляет собой классификацию иного порядка и носит функциональный характер.

\section{Выводы}

Терминология клинической медицины включает сложные термины, образованные композитными и некомпозитными способами. Выделение в особую группу композитных способов словообразования базируется на широ- ком понимании композиции как объединения в одном словообразовательном акте нескольких основ. Среди проанализированных терминов клинической медицины в немецком языке данными способами образованы 98 \% единиц. По типу производящей базы композитные способы делятся на морфологические (на базе слова) и морфолого-синтаксические (на базе словосочетания). Последние представлены реже $(2,7 \%$ терминов). По количеству процессов в словообразовательном акте выделяются способы чистые (только сложение) и смешанные (сложение в сочетании с другими словообразовательными процессами). Чистые способы являются более продуктивными (93,4 \% терминов). Среди композитных способов терминообразования в немецкой клинической терминологии доминирует морфологическое словосложение. Данный способ применительно к медицинской терминологии может быть дифференцирован в зависимости от типа складываемых компонентов: сложение нескольких слов (собственно словосложение); сложение основы / ТЭ с самостоятельным термином; сложение основы / ТЭ с финальным ТЭ (сложным или псевдосложным). Наиболее продуктивны в немецкой клинической терминологии сложение ТЭ/ основы термина с самостоятельным термином и собственно словосложение. Признание ТЭ структурной составляющей композита и опора на него в классификации способов словообразования позволяет, с одной стороны, отказаться от чрезмерного расширения переходной зоны, с другой - провести границу между способами и моделями в терминологическом словообразовании с участием компонентов греко-латинского происхождения. Группировка моделей может быть произведена по критериям, от-

Таблииа 5

Количественная представленность двухкомпонентных композитов с морфемами переходной зоны

\begin{tabular}{|c|c|c|c|}
\hline $\begin{array}{c}\text { Способ } \\
\text { терминообразования }\end{array}$ & Модель термина & $\begin{array}{c}\text { Кол-во } \\
\text { терминов }\end{array}$ & $\%$ \\
\hline \multirow[t]{2}{*}{ Сложение с термином } & Основа / корневой ТЭ + термин & 972 & 63,2 \\
\hline & Частотный компонент + термин & 134 & 8,7 \\
\hline \multirow[t]{2}{*}{ Сложение со сложным ТЭ } & Основа / корневой ТЭ + сложный ТЭ & 191 & 12,4 \\
\hline & Основа / корневой ТЭ + сложный ТЭ-полуаффикс & 3 & 0,2 \\
\hline \multirow{2}{*}{$\begin{array}{l}\text { Сложение с псевдослож- } \\
\text { ным ТЭ }\end{array}$} & Основа / корневой ТЭ + псевдосложный ТЭ & 234 & 15,2 \\
\hline & Основа / корневой ТЭ + псевдосл ожный ТЭ-полуаффикс & 5 & 0,3 \\
\hline & Итого & 1539 & 100,0 \\
\hline
\end{tabular}


личным от словообразовательных, например, по генетическому, который релевантен для медицинской терминологии. Анализ материала в этом аспекте показал, что в немецкой клинической терминологии преобладают термины-гибриды с участием немецких компонентов; из гомогенных композитов греческие представлены шире, чем латинские и немецкие.

Предложенные классификации призваны учесть словообразовательную специфику медицинской терминосистемы в сравнении со словообразованием общеупотребительной лексики и могут быть применены к материалу медицинских терминосистем других языков для обеспечения возможности их корректного сопоставления.

\section{СПИСОК ЛИТЕРАТУРЫ}

Архипова Д. А., Гущина Л. Н., 2012. Сравнительносопоставительный анализ английских и русских онкологических терминов (опухоли центральной нервной системы) // Журнал Гродненского государственного медицинского университета. № 3. С. 75-77.

Ваганова Н. В., 2013. Морфемный статус препозитивного элемента multi- (мульти-) в английском и русском языках // Вестник Нижегородского университета им. Н.И. Лобачевского. № 1. C. 36-40.

Виноградов В. В., 1975. Вопросы современного русского словообразования // Избранные труды. Исследования по русской грамматике / ред. Н. Ю. Шведова. М. : Наука. С. 155-165.

Груздева Н. В., 2012. Понятие и состав «переходной зоны» в словообразовании немецкого языка // Вестник Православного Свято-Тихоновского гуманитарного университета. Серия III: Филология. Вып. 1 (27). С. 22-31.

Гудилова С. В., 2005. Продуктивные типы образования сложных слов в современном русском языке (на материале неологизмов второй половины XX в.) : дис. ... канд. филол. наук. М. $306 \mathrm{c}$.

Гущина Л. Н., 2003. К вопросу об аффиксоидах // Журнал Гродненского государственного медицинского университета. № 2. С. 19-24.

Данилина Н. И., 2012. О специфических словообразовательных типах в медицинской терминологии // Scripta manent : материалы всерос.науч.-практ. конф. «Классические языки в высшей школе» (г. Казань, 2-5 ноября 2012 г.). Казань : КГМУ : КазДС. С. 42-49.
Жилюк С. А., 2016. Гибридное словосложение имен существительных в немецком языке (на материале современных СМИ) // Романо-германистика : сб. ст. по материалам XLV Междунар. филол. конф. (г. Санкт-Петербург, 14-21 марта 2016 г.) / отв. ред. Н. Г. Мед, Н. А. Шадрина, Т. И. Петухова. СПб. : ВВМ. С. 11-15.

Иванова Т. К., Аржанцева Н. В., 2012. Терминосистема сопоставительного словосложения русского, немецкого и английского языков // Вестник Челябинского государственного университета. Вып. 62, № 2 (256). С. 30-37.

Лейчик В. М., 2007. Терминоведение: предмет, методы, структура. Изд. 3-е. М. : ЛКИ. 256 с.

Носачёва М. И., 2017. Особенности немецкого субстантивного композитного терминообразования на основе греко-латинских терминоэлементов в сопоставлении со словообразовательными особенностями русских клинических терминов // Вестник Нижегородского университета им. Н.И. Лобачевского. № 4. C. $183-189$.

Носачёва М. И., 2018. Типология конечных терминоэлементов греко-латинского происхождения в составе клинических композитных терминов // Национальные коды европейской литературы в диахроническом аспекте: античность - современность : коллектив. моногр. / отв. ред. Т. А. Шарыпина, И. К. Полуяхтова, М. К. Меньщикова. Н. Новгород : ДЕКОМ. C. $43-50$.

Русская грамматика, 1980. В2 т. Т. 1 / гл. ред. Н. Ю. Шведова. М. : Наука. 783 с.

Степанова М. Д., 1953. Словообразование современного немецкого языка. М. : Изд-во лит. на иностр. яз. $377 \mathrm{c}$.

Степанова М. Д., Фляйшер В., 1984. Теоретические основы словообразования в немецком языке. М. : Высш. шк. 264 с.

Федорцова В. Н., 1984. Словообразовательные модели существительных с иноязычными компонентами в современном немецком языке (на материале медицинских текстов) : дис. ... канд. филол. наук. Л. $341 \mathrm{c}$.

Хакимова Г. А., 2018. Способы словообразования ветеринарной терминологии в немецком языке // Филологические науки. Вопросы теории и практики. № 10 (88), ч. 1. С. 183-192.

Юшкова Л. А., 2018. Терминологическая множественность в словообразовании (на примере термина «глагольные единицы с именными частицами» и его дублетов) // Вестник Удмуртского университета. Серия: История и филология. Т. 28, № 6. С. 913-920.

Behaghel O., 1930. Die deutsche Sprache. Leipzig : Freytag Verlag. $403 \mathrm{~S}$. 
Eichinger L. M., 2000. Deutsche Wortbildung. Eine Einführung. Tübingen : Gunter Narr Verlag. $269 \mathrm{~S}$.

Eichler W., Bünting K-D., 1996. Deutsche Grammatik: Form, Leistung und Gebrauch der Gegenwartssprache. 6 Aufl. Weinheim : Beltz Athenäum Verlag. $313 \mathrm{~S}$.

Elsen H., 2005. Deutsche Konfixe // Deutsche Sprache: Zeitschrift für Theorie, Praxis, Dokumentation. T. 33. S. 133-140.

Elsen H., 2009. Affixoide: Nur was benannt wird, kann auch verstanden werden // Deutsche Sprache: Zeitschrift für Theorie, Praxis, Dokumentation. T. 37. S. 316-333.

Elsen H., Dzikowicz E., 2005. Neologismen in der Zeitungssprache // Deutsch als Fremdsprache. Zeitschrift zur Theorie und Praxis des Deutschunterrichts für Ausländer. Heft 2. S. 80-85.

Elsen H., Michel S., 2007. Wortbildung im Sprachgebrauch. Desiderate und Perspektiven einer etablierten Forschungsrichtung // Muttersprache. Vierteljahresschrift für deutsche Sprache. Heft 1. S. 1-16.

Engel U., 1994. Syntax der deutschen Gegenwartssprache. Berlin : Erich Schmidt Verlag. 316 S. (Grundlagen der Germanistik).

Grimm J., 1831. Deutsche Grammatik. In 4 Bänden. Dritter Teil. Göttingen : Dieterich Verlag. $810 \mathrm{~S}$.

Henzen W., 1957. Deutsche Wortbildung // Sammlung kurzer Grammatiken germanischer Dialekte. № 5. Tübingen : Niemeyer Verlag. $306 \mathrm{~S}$.

Meillet A., 1908. Introduction à l'étude comparative des langues indo-européennes. Paris : Libr'airie Hachette et C. 464 p.

Michel S., 2011. Affixoide und Konfixe als „konstruktionelleIdiome“? Eine konstruktionsgrammatische Analyse das Affixoid-und Konfixbegriffes. URL: http:// www.uni-koblenz-landau.de/de/koblenz/fb2/ik/ institut/medienwissenschaft/smichel/ 3innsbruck2011.pdf(date of access: 06.01.2018).

Schleicher A., 1861. Compendium der vergleichenden Grammatik der indogermanischen Sprachen. Weimar : Hermann BöhlauVerlag. 764 S.

\section{ИСТОЧНИКИ И СЛОВАРИ}

Бартков - Бартков Б. И. Дериватарий (количественный «словарь» аффиксов) современного английского языка. Казань : Бук, 2018. 318 с.

Петров - Петров А. В. Гнездовой толково-словообразовательный словарь композитов. Симферополь : [б. и.], 2003. 286 с.

Bußmann - Bußmann H. Lexikon der Sprachwissenschaft. Stuttgart : Alfred Kröner Verlag, 1990. $904 \mathrm{~S}$.
Roche Lexikon Medizin - Roche Lexikon Medizin. URL: https://www.roche.de/lexikon/index.htm? userInput=Suche\%20im\%20Roche\%20Lexikon

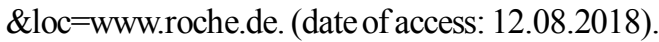

\section{REFERENCES}

Arkhipova D.A., Gushchina L.N., 2012. Sravnitelnosopostavitelnyy analizangliyskikh I russkikhonk ologicheskikh terminov (opukholi tsentralnoy nervnoy sistemy) [Comparative Analysis of the English and Russian Oncological Terms (Denoting Tumors of the CNS)]. Zhurnal Grodnenskogo meditsinskogo universiteta [Journal of Grodno State Medical University], no. 3, pp. 75-77.

Vaganova N.V., 2013. Morfemnyy status prepozitivnogo elementa multi- (multi-) v angliyskom I russkom yazykakh [Morphemic Status of the Prepositional Unit Multi- (мульти-) in the English and Russian Languages]. Vestnik Nizhegorodskogo universiteta im. N.I. Lobachevskogo [Vestnik of Lobachevsky University of Nizhni Novgorod], no. 1 , pp. 36-40.

Vinogradov V.V., 1975. Voprosy sovremennogo russkogo slovoobrazovaniya [Issues of Contemporary Russian Word-Formation]. Shvedova N.Yu., ed. Izbrannye trudy. Issledovaniya po russkoy grammatike [Selected Works. Studies of the Russian Grammar]. Moscow, Nauka Publ., pp. 155-165.

Gruzdeva N.V., 2012. Ponyatie i sostav «perekhodnoy zony» v slovoobrazovanii nemetskogo yazyka [The Concept and the Structure of the "Intermediate Zone" in the German WordBuilding]. Vestnik pravoslavnogo SvyatoTikhonovskogo gumanitarnogo universiteta. Seriya III: Philologiya [St. Tikhon's University Review. Series III: Philology], iss. 1 (27), pp. 22-31.

Gudilova S.V., 2005. Produktivnye tipy obrazovaniya slozhnykh slov v sovremennom russkom yazyke (na material neologizmov vtoroy poloviny $X X$ v.): dis. ... kand. filol. nauk [Productive Types of Compound Word-Building in the Contemporary Russian Language (On the Material of Neologisms of the Second Half of the $20^{\text {th }}$ Century). Cand. philol. sci. diss]. Moscow. 306 p.

Gushchina L.N., 2003. K voprosu ob affiksoidakh [Revisited Affixoids]. Zhurnal Grodnenskogo meditsinskogo universiteta [Journal of Grodno State Medical University], no. 2, pp. 19-24.

Danilina N.I., 2012. O spetsificheskikh slovoobrazovatelnykh tipakh $\mathrm{v}$ meditsinskoy terminologii [About Specific Word-Building Types 
in Medical Terminology]. Scripta manent: materialy vserossiyskoy nauchno-prakticheskoy konferentsii «Klassicheskie yazyki $v$ vysshey shkole» (g. Kazan, 2-5 noyabrya 2012 g.) [Scripta Manent. Proceedings of the All-Russian Scientific and Ptactical Conference "Classical Languages in Higher Education Institutions" (Kazan, November 2-5, 2012)]. Kazan, KGMU Publ., KazDC Publ., pp. 42-49.

Zhilyuk S.A., 2016. Gibridnoe slovoslozhenie imen sushchestvitelnykh vnemetskom yazyke (na material sovremennykh SMI) [Hybrid Compound WordBuilding of Substantives in the German Language (Based on Modern Mass Media)]. Med N.G., Shadrina N.A., Petukhova T.I., eds. Romanogermanistika: sbornik statey po materialam XLVMezhdunarodnoy philologicheskoy konferentsii (g. Sankt-Peterburg, 14-21 marta 2016g.) [Romano-Germanic Studies. Proceedings of the $45^{\text {th }}$ International Philological Conference (Saint Petersburg, March 14-21, 2016)]. Saint Petersburg, BBM Publ., pp. 11-15.

Ivanova T.K., Arzhantseva N.V., 2012. Terminosistema sopostavitelnogo slovoslozheniya russkogo, nemetskogo i angliyskogo yazykov [Terminological System of the Comparative Compound Word-Building of the Russian, German and English Languages]. Vestnik Chelyabinskogo gosudarstvennogo universiteta [Bulletin of Chelyabinsk State University], iss. 62, no. 2 (256), pp. 30-37.

LeychikV.M., 2007. Terminovedenie: predmet, metody, struktura [Terminology Science: Subject, Methods, Structure]. Moscow, LKI Publ. 256 p.

Nosacheva M.I., 2017. Osobennosti nemetskogo substantivnogo kompozitnogo terminoobrazovaniya na osnove greko-latinskikh terminoelementov $\mathrm{v}$ sopostavlenii so slovoobrazovatelnymi osobennostyami russkikh klinicheskikh terminov [Characteristics of the German Substantive Composite Term-Formation on the Basis of the Greek and Latin Terminological Elements in Comparison with the Russian Clinical Terms]. Vestnik Nizhegorodskogo universiteta im. N.I. Lobachevskogo [Vestnik of Lobachevsky University of Nizhni Novgorod], no. 4, pp. 183-189.

Nosacheva M.I., 2018. Tipologiya konechnykh terminoelementov greko-latinskogo proiskhozhdeniya $\mathrm{v}$ sostave klinicheskikh kompozitnykh terminov [Typology of the Final Greek-Latin Terminoelements in the Clinical Compound Terms]. Sharypina T.A., Poluyakhtova I.K., Menshchikova M.K., eds. Natsionalnye kody evropeyskoy literatury $v$ diakhronicheskom aspekte: antichnost - sovremennost: kollektivnaya monografiya [National Codes of the European Literature in Diachronic Aspect: Antiquity Modernity. Collective Monograph]. Nizhniy Novgorod, Dekom Publ., pp. 43-50.

Russkaya grammatika. V2 t. T. 1 [Russian Grammar. In 2 Vols. Vol. 1], 1980. Moscow, Nauka Publ. 783 p.

Stepanova M.D., 1953. Slovoobrazovanie sovremennogo nemetskogo yazyka [WordFormation of the Contemporary German Language]. Moscow, Izd-vo literatury na inostrannykh yazykakh. $377 \mathrm{p}$.

Stepanova M.D., Fleisher W., 1984. Teoreticheskie osnovy slovoobrazovaniya $v$ nemetskom yazyke [Theoretical Base of Word-Formation in the German Language]. Moscow, Vysshaya shkola Publ. 264 p.

Fedortsova V.N., 1984. Slovoobrazovatelnye modeli sushchestvitelnykh s inoyazychnymi komponentami v sovremennom nemetskom yazyke (na material meditsinskikh tekstov): dis. ... kand. philol. nauk [Word-Building Models of Substantives with Foreign Components in the Contemporary German Language (Based on Medical Texts). Cand. Philol. Sci. Abs. Diss.]. Leningrad. 341 p.

Khakimova G.A., 2018. Sposoby slovoobrazovaniya veterinarnoy terminologii v nemetskom yazyke [Ways of Forming Veterinary Terminology in the German Language]. Philologicheskie nauki. Voprosy teorii i praktiki [Philological Sciences. Issues of Theory and Practice], no. 10 (88), part 1, pp. 183-192.

Yushkova L.A., 2018. Terminologicheskaya mnozhestvennost $\mathrm{v}$ slovoobrazovanii (na primere termina «glagolnye edinitsy s imennymi chastitsami» i ego dubletov) [Terminological Plurality in Word Formation (Based on the Term "Verbal Units with Nominal Particles" and Its Synonyms)].Vestnik Udmurtskogo universiteta. Seriya Istoriya i Philologiya [Bulletin of Udmurt University. Series History and Philology], vol. 28, no. 6, pp. 913-920.

Behaghel O., 1930. Die deutsche Sprache. Leipzig, Freytag Verlag. $403 \mathrm{~S}$.

Eichinger L.M., 2000. Deutsche Wortbildung. Eine Einführung. Tübingen, Gunter Narr Verlag. $269 \mathrm{~S}$.

Eichler W., Bünting K-D., 1996. Deutsche Grammatik: Form, Leistung und Gebrauch der Gegenwartssprache. Weinheim, Beltz Athenäum Verlag. $313 \mathrm{~S}$.

Elsen H., 2005. Deutsche Konfixe. Deutsche Sprache: Zeitschrift für Theorie, Praxis, Dokumentation, vol. 33, S. 133-140.

Elsen H., 2009. Affixoide: Nur was benannt wird, kann auch verstanden werden. Deutsche Sprache: 
Zeitschrift für Theorie, Praxis, Dokumentation, vol. 37, S. 316-333.

Elsen H., Dzikowicz E., 2005. Neologismen in der Zeitungssprache. Deutsch als Fremdsprache. Zeitschrift zur Theorie und Praxis des Deutschunterrichts für Ausländer, booklet 2, S. 80-85.

Elsen H., Michel S., 2007. Wortbildung im Sprachgebrauch. Desiderate und Perspektiven einer etablierten Forschungsrichtung. Muttersprache. Vierteljahresschrift für deutsche Sprache, booklet 1, S. 1-16.

Engel U., 1994. Syntax der deutschen Gegenwartssprache. Berlin, Erich Schmidt Verlag. 316 S. (Grundlagen der Germanistik).

Grimm J., 1831. Deutsche Grammatik. In 4 Bänden. Dritter Teil. Göttingen, Dieterich Verlag. $810 \mathrm{~S}$.

Henzen W., 1957. Deutsche Wortbildung. Sammlung kurzer Grammatiken germanischer Dialekte. Tübingen, Niemeyer Verlag., no. 5. 306 p.

Meillet A., 1908. Introduction à l'étude comparative des langues indo-européennes [Introduction Into the Comparative Studies of the Indo-European Languages]. Paris, Libr'airie Hachette et C. 464 p. Michel S., 2011. Affixoide und Konfixe als „,konstruktionelle Idiome“? Eine konstruktionsgrammatische Analyse des
Affixoid-und Konfixbegriffes. URL: http:// www.uni-koblenz-landau.de/de/koblenz/fb2/ik/ institut/medienwissenschaft/smichel/ 3innsbruck2011.pdf(accessed 6 January 2018).

Schleicher A., 1861. Compendium der vergleichenden Grammatik der indogermanischen Sprachen. Weimar, Hermann Böhlau Verlag. 764 p.

\section{SOURCES AND DICTIONARIES}

Bartkov B.I. Derivatariy (kollichestvennyy «slovar» affiksov) sovremennogo angliyskogo yazyka [Derivatariy (Quantity “Dictionary" of Affixes) of the Contemporary English Language]. Kazan, Buk Publ., 2018. 318 p.

Petrov A.V. Gnezdovoy tolkovo-obrazovatelnyy slovar kompozitov [Nest Explanatory and WordFormation Dictionary of Compounds]. Simferopol, 2003. 286 p.

Bußmann H. Lexikon der Sprachwissenschaft [Lexicon of Linguistics]. Stuttgart, Alfred Kröner Verlag, 1990. $904 \mathrm{~S}$.

Roche Lexikon Medizin [Roche Lexicon Medicine]. URL: https://www.roche.de/lexikon/index.htm? userInput $=$ Suche $\% 20 \mathrm{im} \% 20$ Roche $\%$ 20Lexikon $\& l o c=$ www.roche.de (accessed 12 August 2018)

\section{Information about the Authors}

Marina I. Nosacheva, Postgraduate Student, Department of Russian and Latin Languages, Saratov State Medical University named after V.I. Razumovsky, Bolshaya Kazachya St., 112, 410012 Saratov, Russia,sgu0308@yandex.ru,https://orcid.org/0000-0001-6734-0067

Nataliya I. Danilina, Doctor of Sciences (Philology), Associate Professor, Department of Russian and Latin Languages, Saratov State Medical University named after V.I. Razumovsky, Bolshaya Kazachya St., 112, 410012 Saratov, Russia, danilina_ni@mail.ru, https://orcid.org/0000-0001-8804-2157

\section{Информация об авторах}

Марина Игоревна Носачёва, аспирант кафедры русского и латинского языков, Саратовский государственный медицинский университет им. В.И. Разумовского, ул. Большая Казачья, 112, 410012 г. Саратов, Россия, sgu0308@yandex.ru, https://orcid.org/0000-0001-6734-0067

Наталия Ивановна Данилина, доктор филологических наук, доцент кафедры русского и латинского языков, Саратовский государственный медицинский университет им. В.И. Разумовского, ул. Большая Казачья, 112, 410012 г. Саратов, Россия, danilina_ni@mail.ru, https://orcid.org/0000-0001-8804-2157 